\title{
Treatment with Methisazone of Complications Following Smallpox Vaccination
}

\author{
BARBARA JAROSZYŃSKA-WEINBERGER \\ From the Department of Infectious Diseases of Childhood, Medical Academy of Warsaw
}

\begin{abstract}
Jaroszyńska-Weinberger, B. (1970). Archives of Disease in Childhood, 45, 573. Treatment with methisazone of complications following smallpox vaccination. The therapeutic effect of methisazone was studied in a group of 50 children who were suffering from infective complications of smallpox vaccination, such as ectopic primary lesions of the orbit, face, or mouth, eczema vaccinatum, and vaccinia. In 16 children with ectopic lesions who were treated with methisazone by mouth in total doses of 3.2-14.0 g., the mean healing time was $13 \cdot 3$ days, compared with $17 \cdot 8$ days in a control group of 23 similarly infected children who were not treated with methisazone. The difference did not attain significance, but there was a highly significant difference $(p<0.01)$ in the number of cases in which healing occurred within 6 days (13 in the methisazone group and 6 in the control group). In 5 children accidental infection with vaccinia occurred, though antivaccinial $\gamma$-globulin had been given 5-10 days previously. Methisazone was also given to 4 children with eczema vaccinatum and 2 with localized vaccinia gangrenosa. The treatment appeared to be beneficial in comparison with control groups of 3 and 2 children, respectively, but the groups were too small for precise assessment. Methisazone appeared to accelerate the healing of the lesions in 3 children when applied locally.
\end{abstract}

Until recently the treatment of complications of smallpox vaccination has been exclusively symptomatic. However, during the past decade specific therapeutic measures have become available. In addition to antivaccinial $\gamma$-globulin, which may be of value in skin complications such as generalized vaccinia (Kempe, Berge, and England, 1956; Kempe, 1960; Sussman and Grossman, 1965), there now exists the possibility of using chemotherapeutic agents. One of these is methisazone (1-methylisatin 3-thiosemicarbazone) which was first used for therapeutic purposes in 1962 in a case of eczema vaccinatum with a favourable outcome (Turner, Bauer, and Nimmo-Smith, 1962). This compound is also effective in the prevention of smallpox in persons who have been in contact with the disease (Bauer et al., 1963). Several reports have also appeared on the treatment of complications of smallpox vaccination with methisazone, with favourable results (Adels and Oppé, 1966; Barlow, 1962; Daly and Jackson, 1962; Hansson, Johansson, and Vahlquist, 1966) or doubtful (Connolly, Dick, and Field, 1962;

Received 20 February 1970.
Flewett and Ker, 1963; White, 1963). In a continuation of previous work on the prophylaxis of vaccination reactions with methisazone and $\gamma$-globulin (Jaroszyńska-Weinberger and Mészáros, 1966), the results of a study of the therapeutic value of methisazone in complications of smallpox vaccination are now presented.

\section{Materials and Methods}

Between June 1964 and December 1967, 50 children with abnormal infections with vaccinia virus resulting from primary smallpox vaccination or from autoinoculation or contact with vaccinated persons were observed and treated at the Department for Infectious Diseases of Childhood and the Smallpox Vaccination Centre for Children with Contraindications (Section for Vaccination and Control of Infectious Diseases of the Urban Public Health and Epidemiological Station) in Warsaw. They ranged in age from 9 months to 8 years; 22 were treated with methisazone (obtained from the Wellcome Foundation Limited, London), and the remaining 28 did not receive the drug.

In both groups of children general treatment was given (antibiotics-mainly penicillin, calcium gluconate, promethazine, vitamins, and in some cases corticosteroids), or local treatment (Rivanol, $1 \%$ gentian violet, 
anti-inflammatory ointment, sometimes with the addition of hydrocortisone). In addition, 19 children were given $\gamma$-globulin by intramuscular injection, including 8 in the group not treated with methisazone (4.5-15 ml., equivalent to $0.2-0.8 \mathrm{ml} . / \mathrm{kg}$.) and 11 in the treated group (3.0-7.5 ml., equivalent to $0.2 \mathrm{ml} . / \mathrm{kg}$.). The $\gamma-$ globulin used was a $15 \%$ solution of Polish manufacture, prepared from the blood of revaccinated donors, which, as shown previously (Mészáros, Jaroszyńska-Weinberger, and Kręska, 1965) could be regarded as an antivaccinial $\gamma$-globulin.

Methisazone was given as a $20 \%$ suspension in syrup in initial dose of 100-150 mg./kg., followed by $150 \mathrm{mg} . /$ $\mathrm{kg}$. daily for 3-7 days. The total dose given ranged in individual cases from 3.2 to $17.0 \mathrm{~g}$. In addition, the drug was applied locally to the vaccinial lesions in 3 children.

The type and frequency of the complications observed are shown in Table I. The groups are similar in the type and frequency of the complications, but the individual groups are not large and it is not possible to carry out precise comparison between the treated and untreated patients. Table II presents the cases of accidental vaccination ( 39 children). The remaining 11 cases, 7 of eczema vaccinatum and 4 of vaccinia gangrenosa, are described as individual clinical observations.

\section{Results}

Table II compares 39 cases of accidental vaccina-
TABLE I

Patients with Complications after Smallpox Vaccination, Treated and Not Treated with Methisazone

\begin{tabular}{|c|c|c|c|}
\hline \multirow{2}{*}{\multicolumn{2}{|c|}{ Type of Complication }} & \multicolumn{2}{|c|}{ No. of Cases } \\
\hline & & Untreated & Treated \\
\hline Accidental vaccination & $\begin{array}{l}\text { Orbit } \\
\text { Face, around } \\
\text { nose } \\
\text { Tongue and } \\
\text { buccal } \\
\text { mucosa }\end{array}$ & $\begin{array}{r}13 \\
7 \\
3\end{array}$ & $\begin{array}{l}7 \\
6 \\
3\end{array}$ \\
\hline $\begin{array}{l}\text { Eczema vaccinatum } \\
\text { Vaccinia gangrenosa }\end{array}$ & & $\begin{array}{l}3 \\
2\end{array}$ & $\begin{array}{l}4 \\
2\end{array}$ \\
\hline Total & & 28 & 22 \\
\hline
\end{tabular}

tion (16 treated with methisazone and 23 untreated) or from the point of view of two criteria which enable a $\omega$ comparison to be made between the treated and $\mathrm{O}$ untreated groups; (A) the length of time after $\vec{T}$ infection when the vaccinial lesion healed; $(B)$ the number of days elapsing between the appearance of the accidental vaccinial lesion on the skin and its $\stackrel{\oplus}{+}$ healing, defined as the onset of drying up of the $\vec{\theta}$ lesion and scab formation.

A statistical analysis is given in Table III. The

Methisazone in Treatment of Accidental S

\begin{tabular}{|c|c|c|c|c|c|}
\hline \multirow[b]{2}{*}{ Site } & \multirow[b]{2}{*}{ Case No. } & \multirow[b]{2}{*}{ Age (yr.) } & \multicolumn{2}{|c|}{ Not Treated with Methisazone } & \multirow{2}{*}{ 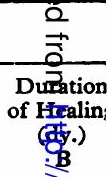 } \\
\hline & & & $\begin{array}{l}\text { Day of } \\
\text { Appearance } \\
\text { of Lesion }\end{array}$ & $\begin{array}{l}\text { Day of } \\
\text { Healing } \\
\text { of Lesion* } \\
\text { A }\end{array}$ & \\
\hline $\begin{array}{l}\text { Orbit } \\
\text { Orbit } \\
\text { Orbit } \\
\text { Orbit } \\
\text { Orbit } \\
\text { Orbit } \\
\text { Orbit } \\
\text { Orbit } \\
\text { Orbit } \\
\text { Orbit } \\
\text { Orbit } \\
\text { Orbit } \\
\text { Orbit } \\
\text { Tongue and buccal mucosa } \\
\text { Tongue and buccal mucosa } \\
\text { Tongue and buccal mucosa } \\
\text { Face (nose and mouth) } \\
\text { Face (nose and mouth) } \\
\text { Face (nose and mouth) } \\
\text { Face (nose and mouth) } \\
\text { Face (nose and mouth) } \\
\text { Face (nose and mouth) } \\
\text { Face (nose and mouth) } \\
\end{array}$ & $\begin{array}{l}1 \\
2 \\
3 \\
4 \\
5 \S \\
6 \\
7 \\
8 \\
9 \\
10 \\
11 \\
12 \\
13 \\
14 \\
15 \\
16 \\
17 \\
18 \\
19 \\
20 \S \\
21 \\
22 \\
23 \\
\end{array}$ & $\begin{array}{l}5 \\
2 \\
7 \\
2 \\
4 \\
4 \\
2 \\
7 \\
4 \\
3 \\
3 \\
2 \\
6 \\
2 \\
2 \\
2 \\
1 \\
3 \\
3 \\
8 \\
2 \\
4 \\
7\end{array}$ & $\begin{array}{r}7 \\
12 \\
7 \\
7 \\
4 \\
8 \\
5 \\
7 \\
7 \\
8 \\
8 \\
3 \\
5 \\
4 \\
9 \\
4 \\
8 \\
8 \\
10 \\
4 \\
6 \\
5 \\
7\end{array}$ & $\begin{array}{l}19 \\
18 \\
19 \\
13 \\
27 \\
15 \\
22 \\
14 \\
16 \\
17 \\
17 \\
13 \\
12 \\
16 \\
23 \\
17 \\
12 \\
14 \\
16 \\
17 \\
33 \\
16 \\
19\end{array}$ & 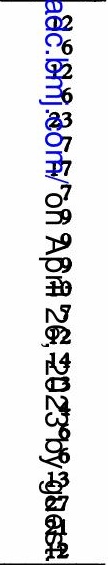 \\
\hline \multicolumn{5}{|c|}{$\begin{array}{l}\text { Notes. The figures in columns } A \text { and } B \text { are analysed statistically in Table III. } \\
\star \text { No. of days after vaccination or accidental contact with the person vaccinated. } \\
\text { tFrom a person recently vaccinated against smallpox. }\end{array}$} & 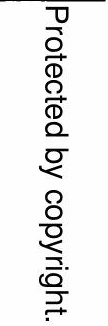 \\
\hline
\end{tabular}


figures for the untreated group in column A (Table II), indicating the number of days elapsing between vaccination and healing, show a wide range, from 12 to 33 days. For the treated group the corresponding figures are nearer to each other and range from 11 to 15 days after vaccination. The arithmetic means of these values for the untreated and treated groups respectively are $17 \cdot 8$ and $13 \cdot 3$; however, this apparent difference in favour of the treatment is not statistically significant $(p>0 \cdot 2)$.

In comparing the figures in column $\mathrm{B}$, representing the days elapsing between the appearance of the lesions and healing, 6 days was taken as the generally accepted value for the time of drying up of uncomplicated vaccination lesions in normal children (range 6-12 days). A comparative analysis was carried out on the number of cases in the treated and untreated groups in which the healing time did not exceed this limit. This took place in only 6 children of 23 in the untreated group (26\%), whereas in the treated group the lesions healed within this time in 13 of 16 children (81\%). A comparison by means of the $\chi^{2}$ test indicated a statistically significant difference $(p<0.01)$ in favour of the treated group.

On this basis of Table II and the analysis of Table III, it can be stated that the course of healing of accidental vaccination lesions and its completion in relation to the day of vaccination (or infection) is much nearer to the physiological duration in the group treated with methisazone. In this group 8 children received $\gamma$-globulin in addition in doses of 3-6 ml. $(0 \cdot 2 \mathrm{ml} . / \mathrm{kg}$.). In 5 , accidental infection with vaccinia occurred in spite of the administration of $\gamma$-globulin 5-10 days previously (Cases 24, 28, 33,37 , and 38); the remaining 3 (Cases 25,32 , and 39) received the injection on the same day as treatment with methisazone was begun, and in these children a drying up of the lesions was seen as late as 4 days after the start of the combined treatment. It, therefore, does not seem that the administration of $\gamma$-globulin in a dose of $0.2 \mathrm{ml} . / \mathrm{kg}$. played any decisive part in the prevention of accidental vaccination infection and the acceleration of the healing of the lesions in these cases.

In addition to the cases of accidental vaccination described above, 11 children with other complications of vaccination were observed; 7 with eczema vaccinatum and 4 with localized vaccinia gangrenosa. They are presented in Table IV with regard to tne type of treatment given and the duration of illness. In view of the small numbers it is not possible to carry out any valid comparison between the patients who received and did not receive methisazone

accination (Auto- and Heteroinoculated)

\begin{tabular}{|c|c|c|c|c|c|c|c|}
\hline & \multicolumn{7}{|c|}{ Treated with Methisazone } \\
\hline $\begin{array}{l}\text { Dose of } \\
\gamma \text {-globulin } \\
\text { (ml.) }\end{array}$ & Case No. & Age (yr.) & $\begin{array}{c}\text { Day of } \\
\text { Appearance } \\
\text { of Lesion }\end{array}$ & $\begin{array}{c}\text { Day of } \\
\text { Healing } \\
\text { of Lesion } \\
\text { A }\end{array}$ & $\begin{array}{c}\text { Duration } \\
\text { of Healing } \\
\text { (dy.) } \\
\text { B }\end{array}$ & $\begin{array}{l}\text { Dose of } \\
\gamma \text {-globulin } \\
\text { (ml.) }\end{array}$ & $\begin{array}{c}\text { Total Dose } \\
\text { of Methisazone } \\
\text { (g.) }\end{array}$ \\
\hline $\begin{array}{l}4 \cdot 5 \\
6 \cdot 0 \\
9 \cdot 0\end{array}$ & $\begin{array}{l}24 \\
25 \\
26 \\
27 \\
28 \\
29 \\
30\end{array}$ & $\begin{array}{l}3 \\
6 \\
4 \\
4 \\
4 \\
2 \\
3\end{array}$ & $\begin{array}{r}10 \\
8 \\
8 \\
8 \\
10 \\
6 \\
7\end{array}$ & $\begin{array}{l}14 \\
15 \\
14 \\
13 \\
13 \\
11 \\
13\end{array}$ & $\begin{array}{l}4(2) \ddagger \\
7(4) \\
6(2) \\
5(2) \\
3(2) \\
5(3) \\
6(2)\end{array}$ & $\begin{array}{l}3 \cdot 0 \\
6 \cdot 0 \\
3 \cdot 0\end{array}$ & $\begin{array}{r}6 \cdot 0 \\
11 \cdot 0 \\
7 \cdot 0 \\
4 \cdot 4 \\
6 \cdot 0 \\
3 \cdot 2 \\
7 \cdot 0\end{array}$ \\
\hline $\begin{array}{c}9.0 \\
4.5 \\
0 \mathrm{ml} . \text { bloodt }\end{array}$ & $\begin{array}{l}31 \\
32 \\
33 \\
34 \\
35 \S \\
36 \\
37 \\
38 \\
39 \S\end{array}$ & $\begin{array}{l}6 \\
2 \\
4 \\
7 \\
4 \\
6 \\
4 \\
7 \\
2\end{array}$ & $\begin{array}{r}8 \\
5 \\
7 \\
9 \\
5 \\
10 \\
8 \\
10 \\
3\end{array}$ & $\begin{array}{l}13 \\
11 \\
13 \\
15 \\
11 \\
15 \\
15 \\
15 \\
13\end{array}$ & $\begin{array}{r}5(2) \\
6(4) \\
6(2) \\
6(2) \\
6(3) \\
5(2) \\
7(3) \\
5(4) \\
10(4)\end{array}$ & $\begin{array}{l}3 \cdot 0 \\
3 \cdot 0 \\
3 \cdot 0\end{array}$ & $\begin{array}{c}5 \cdot 6 \\
5 \cdot 3 \\
5 \cdot 0 \\
3 \cdot 5 \\
6 \cdot 0 \\
14 \cdot 0 \\
3 \cdot 4 \\
9 \cdot 0 \\
5 \cdot 6 \text { (and locally) }\end{array}$ \\
\hline
\end{tabular}

Figures in brackets indicate number of days of methisazone treatment after which healing (drying up) of lesions was seen. Heteroinoculation (autoinoculation occurred in unmarked cases). 
TABLE III

Statistical Analysis of Data in Table II

\begin{tabular}{|c|c|c|c|c|c|c|}
\hline \multirow{2}{*}{ Group } & \multirow{2}{*}{$\begin{array}{l}\text { No. of } \\
\text { Cases }\end{array}$} & \multicolumn{3}{|c|}{$\begin{array}{c}\text { Duration of Illness (days from time of infection to } \\
\text { healing) }\end{array}$} & \multicolumn{2}{|c|}{$\begin{array}{l}\text { Cases in Which Healing Occurred } \\
\text { within } 6 \text { days }\end{array}$} \\
\hline & & Range & Mean & $\begin{array}{l}\text { Statistical } \\
\text { Analysis }\end{array}$ & No. of Cases & $\begin{array}{l}\text { Statistical } \\
\text { Analysis }\end{array}$ \\
\hline Untreated & 16 & $12-33$ & $\begin{array}{l}17 \cdot 83 \\
13 \cdot 33\end{array}$ & $\begin{aligned} & \operatorname{sigma}^{2}=84 \cdot 4 \\
& \mathrm{n}=39 \\
& \mathrm{t}=1 \cdot 51 \\
& \mathrm{p}>0.2 \\
& \text { not significant }\end{aligned}$ & 13 & 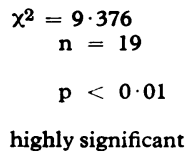 \\
\hline
\end{tabular}

treatment. It is only possible to underline certain observations which became apparent during the consideration of the results.

(1) In Case 46 a visible therapeutic effect was obtained after 2 days of treatment with methisazone in a child with eczema vaccinatum which appeared 8 days after vaccination in the popliteal and antecubital flexures in areas previously affected by eczematous lesions. In view of the history of allergy, vaccination had been carried out under the protection of $3 \mathrm{ml} . \gamma$-globulin given on the same day.

(2) Observations made in the treatment of cases of generalized eczema vaccinatum are worthy of mention, both in the treated and untreated groups.

In 2 children in the group not treated with methisazone the injection of $\gamma$-globulin did not immediately give satisfactory results. In Case 41 the injection was repeated, resulting in an improvement beginning on the 16th day of illness after a total dose of $15 \mathrm{ml}$. Case 42 received $10 \mathrm{ml}$. serum from a person recently vaccinated against smallpox in addition to $\gamma$-globulin, but the response to treatment was negligible. Improvement was observed around the 18th day of treatment in association with the administration of Encorton (a corticosteroid) orally in doses of $1 \mathrm{mg}$. $/ \mathrm{kg}$. for 4 days.

In the group treated with methisazone, on the

TABLE IV

Treatment of Eczema Vaccinatum and Vaccinia Gangrenosa with Methisazone

\begin{tabular}{|c|c|c|c|c|c|c|c|c|}
\hline \multirow{2}{*}{$\begin{array}{c}\text { Type of } \\
\text { Complication }\end{array}$} & \multirow[b]{2}{*}{$\begin{array}{l}\text { Case } \\
\text { No. }\end{array}$} & \multicolumn{3}{|c|}{ Untreated } & \multicolumn{4}{|c|}{ Treated with Methisazone } \\
\hline & & $\begin{array}{l}\text { Age } \\
\text { (yr.) }\end{array}$ & $\begin{array}{c}\text { Duration } \\
\text { (dy.) }\end{array}$ & Notes on Treatment & $\begin{array}{l}\text { Case } \\
\text { No. }\end{array}$ & $\begin{array}{l}\text { Age } \\
\text { (yr.) }\end{array}$ & $\mid \begin{array}{c}\text { Duration } \\
\text { (dy.) }\end{array}$ & Notes on Treatment \\
\hline $\begin{array}{l}\text { Eczema vaccinatum } \\
\text { localized }\end{array}$ & 42 & $\begin{array}{c}3 \\
110 / 12\end{array}$ & $\begin{array}{l}31^{\star} \\
28^{\star}\end{array}$ & $\begin{array}{l}\gamma \text {-globulin, day 6.9 ml. } \\
( \pm) \text { day } 16,6 \mathrm{ml} .(+) \\
\gamma \text {-globulin } 6 \mathrm{ml} .( \pm) ; \\
\text { anti-vaccinial serum } \\
10 \mathrm{ml} .(-) \text {; Encorton } \\
( \pm)\end{array}$ & $\begin{array}{l}45 \\
46\end{array}$ & $\begin{array}{r}1 \frac{1}{2} \\
9 / 12\end{array}$ & $\begin{array}{l}17^{\star} \\
21^{\star}\end{array}$ & $\begin{array}{l}\gamma \text {-globulin } 3 \mathrm{ml} . ; \text { methisa- } \\
\text { zone locally; day } 1(+), \\
\text { day } 2(++) \\
\gamma \text {-globulin } 3 \text { ml. on day } 4 \\
\text { after vaccination; lesions } \\
\text { appeared on day } 8, \\
\text { methisazone } 3 \mathrm{~g} \text {. over } \\
2 \text { days }(+) \\
\gamma \text {-globulin } 4.5 \mathrm{ml} \text {. }(-) ; \\
\text { methisazone } 7.5 \mathrm{~g} . \text { over } \\
5 \text { days; day } 2(+) \text {. } \\
\text { Methisazone } 11 \cdot 2 \mathrm{~g} \text {. over } \\
6 \text { days; day } 3(+)\end{array}$ \\
\hline $\begin{array}{l}\text { Vaccinia gangrenosa } \\
\text { localized }\end{array}$ & 44 & 4 & 35 & $\begin{array}{l}\text { Symptomatic local } \\
\text { Encorton }( \pm)\end{array}$ & 50 & 4 & 35 & 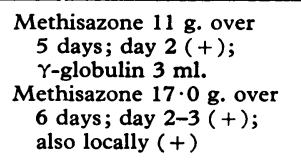 \\
\hline Total no. of cases & 5 & & & & 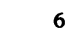 & & & \\
\hline
\end{tabular}

${ }^{\star}$ Heteroinoculation; $(+)$ improvement; $(++)$ visible therapeutic effect; $(-)$ no visible effect of treatment; $( \pm)$ equivocal effect. 
other hand, certain observations were decidedly in favour of the effectiveness of the treatment. In Case 47 treatment with methisazone was begun 3 days after the injection of $4.5 \mathrm{ml} . \gamma$-globulin, which had no apparent effect. Within 48 hours of the administration of methisazone collapse of the lesions and the detachment of scabs was observed, as well as inhibition of the appearance of new vaccinial vesicles. However, in view of the appearance of side-effects (vomiting) treatment was discontinued after 5 days and concluded with other methods, mainly local applications. Particular success was obtained in Case 48, in which treatment was carried out with methisazone only, leading to obvious improvement after 3 days of treatment, which continued from then onwards. In 2 children treated with methisazone (Cases 47 and 48), the generalized eruption healed about 7-10 days earlier than in untreated children who had an illness of similar severity, though, as already mentioned, one cannot draw any conclusions on the basis of the observation of a few cases.

(3) The healing time of post-vaccination ulcers of the type of vaccinia gangrenosa was of similar duration in all cases, as can be seen from Table IV, irrespective of the type of treatment, and amounted to 33-36 days. Apart from this, however, the course of healing was somewhat different with methisazone treatment. Within 1 or 2 days of administration of the drug, a delineation of the excavating lesions became apparent, together with a cessation in appearance of new vaccinial lesions around the margins, and granulation and clearing up of the base of the ulcer. In both cases treatment was interrupted after 5 and 6 days on account of vomiting, and for this reason it was probably not possible to observe the full effect of the treatment.

The results of local application of methisazone were surprisingly good in all 3 cases, which included 1 case each of eczema vaccinatum (Case 45), numerous lesions of accidental vaccination on the face (Case 39), and vaccinia gangrenosa (Case 50). Flattening of the lesions was observed, and regression of the surrounding inflammatory infiltration. The results were particularly worthy of mention in Case 45 (eczema vaccinatum), in which the drug was only used locally, without oral administration; it was smeared unilaterally on an area of the shoulder covered with vaccinial lesions, the other side being left without treatment: drying up and healing of the lesions on the treated side took place considerably more rapidly and came on after 2 days of treatment. In Case 50 (vaccinia gangrenosa) methisazone was used locally after the interruption of oral treatment on account of vomiting; when the suspension was smeared on the edges of the ulcer it appeared to cause further progression of the healing process. In this child the healed lesion, around 30 days after vaccination, was covered with a scab of diameter around $10 \mathrm{~mm}$., similar to that after normal vaccination; the diameter of the ulcer on the day of starting treatment was around $50 \mathrm{~mm}$.

Side-effects seen during oral administration of the drug mainly consisted of vomiting; this occurred in 8 children among 21 who were given the drug by mouth; apart from this, a red coloration was noted in the urine in 2 patients, but no pathological constituents could be found on microscopical and chemical investigation. In 1 child a transient punctate exanthem appeared on the trunk; however, it was uncertain whether this was a result of treatment or a concomitant manifestation of the complication of vaccination.

\section{Discussion}

The results of treatment described concern 3 types of complications of vaccination; accidental vaccination, eczema vaccinatum, and vaccinia gangrenosa.

In accidental vaccinations, which comprised the largest group, good results were obtained from treatment with methisazone. The healing of the lesions, counting from the day of vaccination, was more rapid in the group treated with methisazone (mean 13.3 days) than in the group treated by other methods (mean 17.8 days), though the difference did not attain statistical significance $(p>0 \cdot 2)$. The course of the healing process was nearer to that of the normal reaction to vaccination; the lesions in the children treated with methisazone healed within 6 days in most cases, whereas in the untreated group the duration of healing exceeded this period in a statistically significant number of cases $(p<0.01)$. The course of this complication is generally mild; the lesions heal spontaneously. However, the results of treatment in this group are worth emphasizing in respect of the rapid healing of lesions occurring in unfavourable sites, such as the orbit, nose, buccal mucosa, and tongue.

The results in the cases of eczema vaccinatum are more difficult to interpret on account of the small numbers ( 4 children) in the treated group. However, they are favourable and generally in agreement with those obtained by other authors in similarly small groups (Adels and Oppé, 1966, 2 cases; Barlow, 1962, 1 case; Turner et al., 1962, 1 case; Kempe, 1960, 7 cases). During the course of 2-3 days of treatment with methisazone the skin 
lesions ceased to enlarge and began to heal. As in the reports of the above-quoted authors, our own observations showed that the use of $\gamma$-globulin did not always give immediate and satisfactory results, whereas the introduction of methisazone treatment led to decisive improvement. In two very severe cases of eczema vaccinatum with generalized progressive lesions, healing was complete about 7-10 days earlier (17-21 days) in the group treated with methisazone than in the two equally severe cases in the group treated by other methods (28-31 days), though it is impossible to draw any conclusions in view of the small number of observations.

In the children with non-progressive vaccinia gangrenosa the results of treatment were more indefinite. However, apart from an equal healing time (33-36 days) of the lesions in both groups, in the children treated with methisazone a delimitation of the necrotic areas was observed, and cessation in the appearance of new lesions around the margins of the ulcer, which granulated more rapidly and became shallower. These observations find confirmation in reports in the literature on the favourable results of methisazone treatment in patients with vaccinia gangrenosa who did not react to treatment with $\gamma$-globulin (Hansson et al., 1966; Kempe, 1967).

The results of local treatment with methisazone are worthy of attention. In all 3 cases observed the results were good and consisted of rapid diminution of surrounding oedema and flattening and drying up of the lesions, which proceeded more rapidly than in the areas of skin which were not treated locally. The observations of Connolly et al. (1962) were not so encouraging. They used methisazone as a $10 \%$ ointment in 1 child and observed a toxic-allergic rash which they ascribed to the methisazone treatment; however, this was a very severe case of progressive vaccinia gangrenosa associated with antibody deficiency in which methisazone treatment was carried on for 15 days in spite of the appearance of the above-mentioned manifestations and other side-effects at the 10th day of treatment. Spiess, Käckell, and Schneweis (1966), however, obtained a favourable effect with local injection in experimental animals. These results are worthy of notice in view of the fact which we have stressed that vomiting is a frequent side-effect of oral treatment wich methisazone. In our own cases we observed vomiting in 8 children among 21 treated orally; in 4 this led to the termination of the planned course of treatment. In view of the appearance of side-effects and the possibility of a toxic action, the use of short courses of methisazone seems indicated, as adhered to in our observations.

\section{Histories of Patients Treated with Methisazone}

Case 45. Eczema vaccinatum. A girl aged 2 years from a large family living in bad conditions ( 6 children and 2 adults in 2 rooms). History of infantile eczema treated in the dermatological clinic October-December 1966. On the day of vaccination there was infantile eczema in the stage of improvement, but still with traces of lesions on the skin. Primary vaccination 21 May 1967 without $\gamma$-globulin cover. The lesion healed normally and dried into a scab. On 15 June the child scratched off the scab and transfer of the infection took place to the skin of the shoulders, which were affected by eczema. At the same time the child again became febrile up to $39{ }^{\circ} \mathrm{C}$. She was admitted to hospital on 17 June. On examination the temperature was $38^{\circ} \mathrm{C}$. and the general condition was good. On the skin of the shoulders and arms there were numerous vaccinial lesions, thickly clustered, in places confluent and weeping. The skin was rough, with signs of scratching. At the site of vaccination on the left arm there was a large lesion $25 \mathrm{~mm}$. in diameter, partly covered with a scab. Treatment: penicillin 600,000 units, calcium Sandoz $10 \%, 5 \mathrm{ml}$. injected intramuscularly on 2 successive days, promethazine. In addition methisazone was given locally from 18 June. A $20 \%$ suspension was smeared on the shoulders at the site of the lesions on one side only (left); the right side was left without treatment. Over a period of 24 hours improvement was observed on the side treated with methisazone, in that the lesions ceased weeping and began to dry up. On 19 June, $3 \mathrm{ml}$. $\gamma$-globulin was given intramuscularly, and the skin of the shoulders was treated with methisazone on both sides. On 20 June the skin of the shoulders and arms on both sides was drying up simultaneously. Treatment was discontinued on 21 June, and the course lasted 3 days. Improvement continued during the next few days. On 22 June further local treatment was given with 1:1000 Rivanol solution, for the child was scratching the drying lesions from time to time. Healing was complete on 24 June.

Case 46. Eczema vaccinatum. A boy aged 6 years. History of eczema, treated as an out-patient, with localization of the lesions in the popliteal and anti-cubital fossae. During a period of improvement three attempts were made to carry out smallpox vaccination, all of which gave a negative result. On 27 May 1966 the skin was without eczematous lesions, but was dry and thickened in the popliteal and antecubital fossae. Vaccination against smallpox was carried out that day; 4 days later (31 May) $3 \mathrm{ml} . \gamma$-globulin were given when it was seen that the vaccination had been successful. On 3 June lesions resembling vaccinia appeared in the popliteal fossae, mainly on the right side, and the temperature rose to $38-39{ }^{\circ} \mathrm{C}$. Oral promethazine was prescribed. On 7 June there was no improvement, and new vaccinial lesions had appeared below the nose and in the right nostril; around the lesions in the popliteal fossae there was an inflammatory infiltrate, engorgement of the vessels, and enlargement of the 


\section{Treatment with Methisazone of Complications Following Smallpox Vaccination}

regional lymph nodes. On 7 June oral treatment with methisazone was begun, in the following doses: first day, $5 \mathrm{ml}$; s second day, 2 doses of $2.5 \mathrm{ml}$.; third day, 2 doses of $2.5 \mathrm{ml}$. The total dose was $3 \mathrm{~g}$. Improvement was seen on 8 June, and on 9 June there was complete healing and drying up of the lesions, both in the popliteal fossae and the nose. On 10 June complete healing of all lesions was observed at out-patients. In this case the effect of methisazone was good in spite of the small total dose, which was all retained; the case was not one of generalized eczema vaccinatum, and the lesions were localized in distribution.

The complication arose in spite of the prophylactic administration of $\gamma$-globulin 4 days after vaccination.

Case 47. Generalized eczema vaccinatum. 1 year and 6 months. Infantile eczema since the second month of life; never vaccinated against smallpox. Child's family were vaccinated against smallpox, 21 June 1965. On 26 June the child began to develop pustular lesions on the face, which became confluent and weeping, with fever up to $40{ }^{\circ} \mathrm{C}$.; the lesions which resembled vaccinial vesicles were situated on the eczematous areas and continued to spread. On 28 June $3 \mathrm{ml} . \gamma$-globulin were injected without effect. On 1 and 2 July severe general condition, lesions spreading, weeping, becoming confluent, particularly on the face; doughy oedema of the face and skin of the head developed. On the same day treatment with methisazone was begun, which was given by mouth 3 times a day in a dose of $0.5 \mathrm{~g}$. $(7.5 \mathrm{ml}$. per day). On the second day of treatment ( 3 July) diminution of the oedema of the skin of the face and head was noted, no new lesions appeared, though the temperature was still raised $\left(39^{\circ} \mathrm{C}\right.$.). On 5 July the temperature fell to $38^{\circ} \mathrm{C}$., healing of the lesions was obvious, and the scabs were beginning to become detached; there were no new lesions. However, it was necessary to discontinue methisazone treatment after 5 days as vomiting had occurred on 3 occasions. Further treatment was carried out with other agents; penicillin, erythromycin, promethazine, a further dose of $\gamma$-globulin $(4.5 \mathrm{ml}$.), transfusion of blood and plasma. Further complications set in which required treatment (7 July, subglottal laryngitis; $15 \mathrm{July,} \mathrm{dyspepsia).} \mathrm{By} \mathrm{means} \mathrm{of}$ methisazone it was possible to arrest the further progress of the lesions at the height of their development, but it was not possible to continue with the treatment on account of vomiting. The result obtained was an improvement rather than a cure. Healing of the skin was complete by 12-14 July. The total dose of methisazone in this case amounted to $7.5 \mathrm{~g}$.

Case 48. Generalized eczema vaccinatum. A girl aged 9 months. The patient had not hitherto been vaccinated against smallpox on account of lesions of infantile eczema on the skin. Recently the lesions had been in the phase of healing. She came in contact with vaccinia when her sister was vaccinated. About 2 weeks after contact with the vaccinated sister, the patient developed an exacerbation of the eczema on the cheeks, and on the following day there appeared a generalized eruption of vaccinial lesions with concentration in the area of the vagina and anus, the lids of both eyes (with great swelling), together with involvement of the cheeks, nose, chin, circumoral area, popliteal fossae, and groins. 3 days after the appearance of the lesions, treatment was begun with penicillin and promethazine and after 4 days with methisazone, in the following doses: $200 \mathrm{mg} . / \mathrm{kg}$. on the $1 \mathrm{st}$ day, and $100 \mathrm{mg}$. $/ \mathrm{kg}$. daily for a further 6 days. The total dose of methisazone was $11 \cdot 2 \mathrm{~g}$. The effect of treatment was already noticeable on the 3rd day; the lesions became flattened and began to dry up, and the swelling of the eyelids diminished. Beginning from the 4th day the temperature fell to normal, no further lesions appeared, and the process of healing continued. On the 7th day of treatment a macular erythematous exanthem appeared, localized to the lower limbs and trunk, possibly due to the administration of the drug. Treatment with methisazone was discontinued. The eruption disappeared the next day. Healing of the lesions continued for a few more days. Recovery and healing were complete 21 days after the appearance of the vaccinial lesions.

In this case a marked therapeutic effect was obtained with methisazone and non-specific local and general treatment. $\gamma$-globulin was not given.

Case 49. Vaccinia gangrenosa. A girl aged $4 \frac{1}{2}$ years. Primary smallpox vaccination was carried out on 10 October 1966. Between 4 and 7 days after vaccination a thick black scab formed, about $20 \mathrm{~mm}$. in diameter, from under which turbid fluid was coming. The temperature was $38 \cdot 5-39{ }^{\circ} \mathrm{C}$. Between 8 and 11 days after vaccination the scab underwent demarcation, disclosing a necrotic base of diameter around $30 \mathrm{~mm}$., lying within a crater with punched out walls. The margins of the lesion were raised, with isolated fresh lesions of vaccinial type. The surrounding area of erythema was inconsiderable. On 21 October, 11 days after vaccination, oral treatment with methisazone was begun, and penicillin was given as well. The dose of methisazone was as follows: $1.4 \mathrm{~g}$. (around $100 \mathrm{mg} . / \mathrm{kg}$.) in 1 dose, and on the following 4 days $2 \cdot 4 \mathrm{~g}$. daily (around $100 \mathrm{mg}$./ kg.). Within the first 2 days of treatment the fresh vaccinial lesions around the ulcer appeared to be healing and drying up. No new lesions appeared. On 22 October $3 \mathrm{ml}$. $\gamma$-globulin were given. The lesion healed very slowly, since the cavity was deep; a necrotic scab formed and became detached 3 times during the period of hospitalization, which lasted until the 33rd day after vaccination. On the day of discharge the site of inoculation on the shoulder was covered with a fine scab about $10 \mathrm{~mm}$. in diameter, which had dried level with the surface of the skin.

In this case the administration of methisazone was accompanied by cessation of the development of the lesion and appearance of new ones. This might have been due to the $\gamma$-globulin which was given subsequently, but probably not in view of the low dose $(3 \mathrm{ml}$.) and the weak effect of $\gamma$-globulin on local reactions observed previously (Jaroszyńska-Weinberger and Mészáros, 1966). It was necessary to discontinue methisazone treatment after 
5 days on account of vomiting, and for this reason it is possible that the full therapeutic effect could not manifest itself.

Case 50. Vaccinia gangrenosa. A boy aged 4 years. Primary vaccination on 18 October 1967. After 9 days there was a fairly extensive local reaction, and eruption surrounded by satellite lesions, and later a scab underlain by fluid. The temperature rose again to $39 \cdot 2{ }^{\circ} \mathrm{C}$. between 3 and 5 November and an abscess formed on a deep infiltrate above the site of vaccination on the left shoulder but on the postero-lateral aspect (therefore not due to inflammation of the regional lymph nodes). The abscess became open on 6 November and the contents were purulent. The patient was admitted on 7 November. On admission the temperature was normal and the general condition was good. On the left shoulder there was a necrotic area of diameter around $40-50 \mathrm{~mm}$.; it was deep, with gaping margins. Above the site of vaccination and passing on to the trunk there was a firm red infiltrate, with the crater of the ulcer opening in it and discharging a sero-sanguineous fluid. The base of the necrotic lesion at the site of vaccination was unreactive with no signs of healing. Penicillin was given and methisazone in the following doses: $10 \mathrm{ml}$. on the $1 \mathrm{st}$ day, and $15 \mathrm{ml}$. daily on the following days (around $100 \mathrm{mg}$. $/ \mathrm{kg}$. daily). Oral administration was continued for 6 days, and the total dose of methisazone was $17.0 \mathrm{~g}$. In addition, compresses of $3 \%$ sodium bicarbonate solution were applied locally. Improvement was noted on 9 November on the second day of treatment with methisazone; while the diameter of the ulcer remained unchanged, the base and margins became clean and the base began to granulate. On 10 November the base was continuing to fill out and the diameter of the defect was now $40-45 \mathrm{~mm}$. On 12 November there was further improvement, but on account of vomiting the oral administration of methisazone was discontinued. However, the margins of the lesion were smeared with methisazone for a further 3 days up to and including 14 November. On 15 November the lesion was much shallower, and the diameter was $20 \mathrm{~mm}$. Further treatment consisted only of $1 \%$ gentian violet solution locally. The diameter of the lesion continued as follows: 17 November, $18 \mathrm{~mm}$; 20 November, $13 \mathrm{~mm}$.; on 23 November, the day of discharge, it had healed to a scab level with the skin surface of diameter $10 \mathrm{~mm}$. (the ulcer above the site of vaccination healed around 9 November after 3 days of penicillin treatment; a $\beta$-haemolytic streptococcus of group A was grown from it).

In summary, a good effect was obtained with general and local administration of methisazone in a case of localized vaccinia gangrenosa. The case is worthy of note in that treatment was confined to methisazone and $\overline{\bar{S}}$ no $\gamma$-globulin was given.

\section{REFERENCES}

Adels, B. R., and Oppé, T. E. (1966). Treatment of eczema vaccinatum with $\mathrm{N}$-methylisatin beta-thiosemicarbazone. Lancet, 1, 18.

Barlow, A. J. E. (1962). Drug for vaccinia. British Medical fournal, 1, 1144.

Bauer, D. J., St. Vincent, L., Kempe, C. H., and Downie, A. W. (1963). Prophylactic treatment of smallpox contacts with $\mathrm{N}-$ methylisatin $\beta$-thiosemicarbazone. Lancet, 2, 494.

Connolly, J. H., Dick, G. W. A., and Field, C. M. B. (1962). A ญे fatal case of progressive vaccinia. British Medical fournal, 음 $1,1315$.

Daly, J. J., and Jackson, E. (1962). Vaccinia gangrenosa treated $\vec{c}$ with N-methylisatin $\beta$-thiosemicarbazone. British Medical iN Fournal, 2, 1300.

Flewett, T. H., and Ker, F. L. (1963). A case of vaccinia necrosum (or progressive vaccinia), with severe hypogammaglobulinaemia, treated with n-methylisatin $\beta$-thiosemicarbazone (33T57). fournal of Clinical Pathology, 16, 271.

Hansson, O., Johansson, S. G. O., and Vahlquist, B. (1966). 윽 Vaccinia gangrenosa with normal humoral antibodies. Acta Paediatrica Scandinavica, 55, 264.

Jaroszyńska-Weinberger, B., and Mészáros, J. (1966). A comparison of the protective effect of methisazone and a hyperimmune antivaccinial gamma-globulin in primary smallpox vaccination carried out in the presence of contraindications. Lancet, 1, 948 .

Kempe, C. H. (1960). Studies on smallpox and complications of smallpox vaccination. Pediatrics, 26, 176.

(1967). Discussion. In First International Conference on Vaccines against Viral and Rickettsial Diseases of Man, Washington D.C. 1966 (Pan American Sanitary Bureau, Publications, No. 147), Pan American Health Organization, Washington, D.C.

Berge, T. O., and England, B. (1956). Hyperimmune vaccinial gamma globulin: source, evaluation, and use in prophylaxis and therapy. Pediatrics, 18, 177.

Mészáros, J., Jaroszyńska-Weinberger, B., and Kreska, B. (1965). Serologic studies in children vaccinated against smallpox under protection of gamma globulin or methisazone (Polish). Przeglad Edidemiologiczny, 19, 147.

Spiess, H., Käckell, M. Y., and Schneweis, K. E. (1966). Grundlagen zur Wirkung von Hyperimmunglobin, Vaccineantigen und von Marboran gegen die Vaccinevirusinfektion. Monatsschrift für Kinderheilkunde, 114, 168.

Sussman, S., and Grossman, M. (1965). Complications of smallpox vaccination. Effects of vaccinia immune globulin therapy. Fournal of Pediatrics, 67, 1168.

Turner, W., Bauer, D. J., and Nimmo-Smith, R. H. (1962). Eczema vaccinatum treated with $\mathrm{N}$-methylisatin $\beta$-thiosemicarbazone. British Medical fournal, 1, 1317.

White, C. M. (1963). Vaccinia gangrenosa due to hypogammaglobulinaemia. Lancet, 1, 969.

Correspondence to Dr. D. J. Bauer, The Wellcome Research Laboratories, Langley Court, Beckenham, Kent, BR3 3BS. 